\title{
PROJETOS DE EDUCAÇÃO AMBIENTAL ESCOLAR: UMA PROPOSTA DE AVALIAÇÃO
}

Lúcia Regina Goulart Vilarinho ${ }^{1}$

Cláudia Correia do Rego Monteiro ${ }^{2}$

Resumo: Este estudo teve o objetivo de construir, validar e pré-testar um instrumento de avaliação, para ser aplicado a projetos escolares de Educação Ambiental. Teve como referência a Legislação de Educação Ambiental escolar e duas perspectivas teóricas que tratam, respectivamente, de projetos de aprendizagem e da Educação Ambiental crítica. O instrumento criado foi uma Lista de Verificação, avaliado por 12 especialistas das áreas de avaliação, educação e Educação Ambiental. Entre os resultados destacam-se: o instrumento é adequado para avaliar projetos escolares de Educação Ambiental, sendo válido, portanto, para ser aplicado em escolas de Ensino Fundamental. $O$ instrumento, por conter orientações relevantes, revelou ser também um guia na elaboração de projetos escolares de Educação Ambiental.

Palavras-chave: Avaliação; Educação Ambiental Escolar; Projetos de Aprendizagem; Perspectiva Crítica.

\footnotetext{
${ }^{1}$ Fundação Cesgranrio / RJ. E-mail: luciagvilarinho@gmail.com.

2 Bacharel e licenciada em Ciências Biológicas pela Universidade Santa Úrsula; especialista em Educação Ambiental pela PUC - Rio; Mestre em Avaliação; professora de Ciências e Biologia no Colégio Pedro II; Diretora Pedagógica no Colégio Pedro II, Campus Humaitá II. E-mail: clauregomonteiro16@gmail.com
} 


\section{Educação Ambiental: situando seus principais eventos}

O conceito de Educação Ambiental sempre esteve, de alguma forma, associado ao meio ambiente e ao modo como a sociedade o compreende. $\mathrm{Na}$ década de 70 do século passado inúmeros eventos colocaram em pauta a discussão sobre este tema, podendo ser citados: a Conferência das Nações Unidas sobre o Ambiente Humano (1972 - Estocolmo); a criação do Programa das Nações Unidas para o Meio Ambiente (PNUMA - 1977); o Seminário de Educação Ambiental (1974 - Finlândia); o Encontro Internacional em Educação Ambiental (1975 - Belgrado); a Conferência Intergovernamental de Educação Ambiental (1977 - Conferência de Tbilisi), todos eles construindo as bases da Educação Ambiental e oferecendo subsídios para que, na década de 80 , se concretizassem ações na área do ensino em uma perspectiva interdisciplinar de conteúdos ecológicos. Não foi por acaso que, em 1987, a Estratégia Internacional de Ação no Campo da Educação Ambiental e da Formação em Educação Ambiental para o Decênio de 90 - documento final do Congresso Internacional sobre Educação e Formação Relativas ao Meio-ambiente, promovido em Moscou pela UNESCO, ressaltou a importância da formação de recursos humanos nas áreas formais e não formais da Educação Ambiental, e a inclusão da dimensão ambiental nos currículos de todos os níveis (MINISTÉRIO DO MEIO AMBIENTE, 2017).

Nesta mesma década, aqui no Brasil, o Plenário do Conselho Federal de Educação aprovou por unanimidade a conclusão da Câmara de Ensino a respeito do Parecer 226/87 (MINISTÉRIO DO MEIO AMBIENTE, 1987), que considerou necessária a inclusão da Educação Ambiental entre os conteúdos a serem explorados nas propostas curriculares das escolas de $1^{\circ}$ e $2^{\circ}$ graus, como sugeriam os Centros de Educação Ambiental.

Em 1988, a Constituição da República Federativa do Brasil (BRASIL, 1988) dedicou o Capítulo VI ao Meio Ambiente e no Art. 225, Inciso VI, determinou "[...] ao Poder Público, promover a Educação Ambiental em todos os níveis de ensino [...]", sendo que, na década de 1990, ocorreram algumas mudanças significativas para legitimar a introdução da Educação Ambiental no currículo escolar.

Com a Portaria 678/91 (MINISTÉRIO DA EDUCAÇÃO, 2002, p. 10), determinou-se que "a educação escolar deveria contemplar a Educação Ambiental, permeando todo o currículo dos diferentes níveis e modalidades de ensino, antecedendo a característica transversal do tema meio ambiente". Já a Portaria 2421 (MINISTÉRIO DA EDUCAÇÃO, 1991) instituiu, em caráter permanente, um Grupo de Trabalho de Educação Ambiental com o objetivo de definir, juntamente com as Secretarias Estaduais de Educação, as metas e estratégias para a implantação da Educação Ambiental no país e elaborar uma proposta de atuação do MEC na área da educação formal e não formal para a Conferência da ONU sobre o Meio Ambiente e Desenvolvimento.

A partir desta definição, surgiu o Encontro Nacional de Políticas e 
do Meio Ambiente (SEMA), com apoio da UNESCO/Embaixada do Canadá em Brasília, que teve a finalidade de discutir diretrizes para a definição da Política da Educação Ambiental. Em 1992 ocorre a Conferência da ONU sobre Meio Ambiente e Desenvolvimento, a RIO -92, no Rio de Janeiro, que promoveu um workshop com o objetivo de socializar os resultados das experiências nacionais e internacionais de Educação Ambiental e discutir metodologias e currículos. Do encontro resultou a Carta Brasileira para a Educação Ambiental (DIAS, 2004). O Tratado de Educação Ambiental para Sociedades Sustentáveis e Responsabilidade Global_(1992) reconheceu a Educação Ambiental como um processo de aprendizagem permanente, baseado no respeito a todas as formas de vida.

Finalmente, em 1996, com a nova Lei de Diretrizes e Bases da Educação Nacional (BRASIL, 1998), abriu-se caminho para a inclusão da Educação Ambiental nos Parâmetros Curriculares Nacionais (PCN), fazendo parte da área de Meio Ambiente, situada como um dos temas transversais, centrando seu trabalho pedagógico "no desenvolvimento de atitudes e posturas éticas e, no domínio de procedimentos, mais do que na aprendizagem de conceitos" (MINISTÉRIO DA EDUCAÇÃO, 1998, p. 201).

Em dezembro de 2002, a Assembleia Geral das Nações Unidas, durante sua $57^{a}$ sessão, estabeleceu a Resolução n. 254, declarando 2005 como o início da Década da Educação para o Desenvolvimento Sustentável, depositando na UNESCO a responsabilidade pela implementação da iniciativa (MMA, 2017). E, no ano seguinte (2003), durante a XIV Reunião do Foro de Ministros de Meio Ambiente da América Latina e Caribe, realizada em novembro no Panamá, foi oficializado o Programa Latino-americano e Caribenho de Educação Ambiental (PLACEA), que teve como principal protagonista a Venezuela, e como foro de discussões, a série dos congressos ibero-americanos de Educação Ambiental

Atualmente, pode-se dizer que a definição de Dias (2004, p. 100) sobre Educação Ambiental é um marco nesse histórico aqui sumarizado. Para ele, a Educação Ambiental é "um processo por meio do qual as pessoas apreendem como funciona o ambiente", vendo-se também como dependente dele, como o afetam e como podem prover a sua sustentabilidade. Destaca que ela deve se constituir em um processo contínuo e permanente, através de todas as fases de ensino formal e não formal.

Ao longo desses anos, as discussões sobre Educação Ambiental têm se ampliado nas escolas, o que torna necessário avaliar como a Educação Ambiental é encaminhada a partir de seus projetos. Existem lacunas nos processos de avaliação da Educação Ambiental, levando a se presumir que há espaço para a criação de instrumentos que proponham realizar a avaliação dos projetos escolares de Educação Ambiental, com o objetivo de garantir um feedback aos seus autores. Na prática, se percebe a ausência de instrumentos de avaliação que meçam se os trabalhos realizados estão de acordo com a legislação vigente.

revista brasileira educação ambiental 


\section{A proposta do estudo}

Face ao exposto, elaborou-se o seguinte objetivo para nortear 0 presente estudo: construir, validar e pré-testar um instrumento de avaliação, que seja passível de ser aplicado a projetos de Educação Ambiental escolares, desenvolvidos no Ensino Fundamental II. Tal objetivo se reveste de relevância pelo fato de a Educação Ambiental ser uma prática relativamente nova nas escolas do país; pela inexistência de um instrumento de avaliação que possa ser aplicado genericamente a qualquer projeto escolar de Educação Ambiental; e pela contribuição que pode oferecer a esta prática.

A experiência docente nessa área indicou a ausência de um instrumento de avaliação que avaliasse a qualidade dos trabalhos executados e se eles estão de acordo com a legislação vigente. Tal fato remeteu o estudo para as seguintes questões avaliativas: (a) até que ponto o instrumento de avaliação atende às demandas de documentos e da legislação que norteiam a prática da Educação Ambiental? (c) até que ponto a perspectiva crítica da Educação Ambiental se expressa no instrumento construído?

\section{Recortes teóricos sobre Educação Ambiental}

Para atender ao objetivo proposto, buscou-se subsídios teóricos que pudessem dar sustentação à construção do instrumento de avaliação. Esses subsídios foram retirados dos seguintes conteúdos: Pedagogia de Projetos de Aprendizagem; Pedagogia Ambiental Crítica; Lei de Diretrizes e Bases da Educação Nacional (BRASIL, 1996); Parâmetros Curriculares Nacionais (PCN - BRASIL, 1998); Política Nacional de Educação Ambiental (BRASIL, 1999); e Diretrizes Curriculares Nacionais. Indagou-se, então, o que dizem tais documentos sobre Educação Ambiental Escolar e que contribuições oferecem para a construção de um projeto de aprendizagem.

\section{Projetos de aprendizagem: como desenvolvê-los}

A cultura escolar pode ser vista em duas perspectivas: uma baseada no ensino, sustentada por uma concepção epistemológica empirista, instrucionista, que privilegia o saber do professor, fazendo do espaço educacional um local de hierarquias e o aluno um mero receptor; e a outra baseada em uma concepção epistemológica interacionista-construtivista, tendo como centro do processo educacional o aluno capaz de promover a construção do conhecimento (TREIN; SCHLEMMER, 2009).

No ensino por projetos todas as decisões cabem aos professores, que vão controlar o desenvolvimento do projeto: "não se dá oportunidade ao aluno para qualquer escolha. Não the cabe tomar decisões. Espera-se sua total submissão às regras impostas pelo sistema". (FAGUNDES; SATO; MAÇADA, 2008 , p. 16). Já no desenvolvimento de projetos de aprendizagem favorece-se a experiência da cooperação, a partir do momento em que se coloca em prática o exercício do respeito mútuo, da troca de saberes. Nele, valoriza-se a capacidade de estar sempre aprendendo, de buscar soluções que deem 
margem à formulação de outros problemas mais complexos. Nesta perspectiva, "compreende o desenvolvimento continuado de novas competências em níveis mais avançados, seja do quadro conceitual do sujeito, de seus sistemas lógicos, seja de seus sistemas de valores e de suas condições de tomada de consciência" (FAGUNDES; SATO; MAÇADA, 2008, p. 24).

Trein e Schlemmer (2009) falam que um dos aspectos que diferencia a Pedagogia de Projetos de Aprendizagem baseada em problemas, de metodologias tradicionais, é que o fato de a primeira colocar luz na aprendizagem do sujeito: é o sujeito que aprende. E tal aprendizagem nasce das curiosidades, dúvidas, problematizações individuais e coletivas que vão alimentar a discussão das temáticas a serem investigadas.

Assim, um projeto de aprendizagem deve ter as seguintes bases: (a) fundamentar-se uma perspectiva interacionista-construtivista; (b) quem aprende é o estudante; (c) a aprendizagem se dá de forma colaborativa, cooperativa (interacionista); (d) quem decide o tema de estudo e as questões que o completam é o estudante; (e) é o estudante quem elabora as questões de seu problema; (f) o estudante tem de formular com clareza o seu problema para começar a trabalhar nele; $(\mathrm{g})$ dúvidas, desafios, problematizações fazem parte desta metodologia; (h) as questões formuladas têm a ver com as histórias de vida dos aprendentes, ou seja, elas são extraídas do dia a dia desses sujeitos; (i) a prioridade é o desenvolvimento coletivo de um processo de apreensão de conceitos e ideias, que permita o desabrochar de competências de valores.

Neste sentido, o professor será um orientador e articulador da prática, buscando sempre refletir, pesquisar para garantir aos alunos uma verdadeira aprendizagem.

\section{Educação Ambiental: perspectivas conservadora e crítica}

$\mathrm{Na}$ visão conservadora da Educação Ambiental percebe-se a realidade de forma desintegrada, separando sociedade e natureza. Ela dificulta o pensamento em conjunto, que é capaz de totalizar a complexidade. O mundo é visto de forma partida, fragmentado, em partes, acabando por privilegiar uma dessas partes e estabelecer uma diferença hierarquizada que constrói a lógica da dominação e da espoliação. Esta visão simplifica e reduz a realidade, o que leva a perder-se a riqueza e a diversidade que existem nas relações (GUIMARÃES, 2004, p. 26). Baseada nesta visão, a sua prática pedagógica se torna simplista, reduzida, incapaz de perceber a complexidade da realidade que vai muito além da soma das partes. Na realidade, trata-se de uma prática que visa apenas o indivíduo e a transformação do seu comportamento.

Para Guimarães (2004, p. 27) esta perspectiva conservadora "não contempla a ideia da educação se realizar no movimento de transformação do indivíduo inserido num processo coletivo de transformação da realidade socioambiental, como uma totalidade dialética em sua complexidade". Significa

dizer que a Educação Ambiental conservadora não consegue ver a

revista brasileira educação ambiental 
formação/transformação do sujeito atrelada ao movimento dialético da sociedade.

Loureiro (2007) alerta para o fato de a Educação Ambiental crítica ser muito complexa em relação ao entendimento de conceitos como: natureza, sociedade, ser humano e educação, o que acaba por exigir uma relação profunda entre ciências (sociais ou naturais) e filosofia, capaz de gerar pontes e saberes transdisciplinares. E mais ainda, fala que a "Educação Ambiental crítica não comporta separações entre cultura-natureza, fazendo a crítica ao padrão de sociedade vigente, ao modus operandis da educação formal, à ciência e à filosofia dominante" (LOUREIRO, 2007, p. 68). Diz este autor que a Educação Ambiental deve ser efetivamente autocrítica e chama atenção para o fato de que crítica sem autocrítica "é problematizar o movimento da vida querendo ficar de fora, sem colocar a mão na massa". Para ele, o cerne da Educação Ambiental crítica é a "problematização da realidade, de nossos valores, atitudes e comportamentos em práticas dialógicas" (LOUREIRO, 2007, p. 70). Neste questionar, surge o conceito de conscientização, proposto por Freire (2004), como processo de mútua aprendizagem pelo diálogo, reflexão e ação no mundo.

A Educação Ambiental crítica tem por base outro paradigma. Guimarães (2004) e Loureiro (2007) não defendem uma evolução nos conceitos hegemônicos, mas falam sim de uma contraposição. Percebem a realidade como um movimento dialético/dialógico; nele se dá a interação de forças: conflitos, consensos, relações de poder, em um processo totalizante. No centro desse movimento está a complexidade. Assim, a Educação Ambiental crítica busca promover ambientes educacionais de mobilização desses processos de intervenção na realidade e nos problemas socioambientais, para que se possa superar as visões hegemônicas da realidade.

Buscou-se adotar na elaboração do Quadro de Categorias e Indicadores que orienta a construção do instrumento esta visão crítica da Educação Ambiental.

\section{A Educação Ambiental na Lei de Diretrizes e Bases da Educação Nacional}

A aprovação da nova Lei de Diretrizes e Bases da Educação Nacional (BRASIL, 1996), foi coetânea aos primórdios da Educação Ambiental, assim, existem poucas menções à questão em seu corpo. Há uma referência feita no artigo 32, inciso II, segundo a qual deva ser exigida no Ensino Fundamental, "a compreensão ambiental natural e social do sistema político, da tecnologia, das artes e dos valores em que se fundamenta a sociedade"; e no artigo 36, $\S 11^{\circ}$, "que os currículos do ensino fundamental e médio devem abranger, obrigatoriamente, [...] o conhecimento do mundo físico e natural e da realidade social e política, especialmente do Brasil".

Portanto, o que se especifica é o desenvolvimento de uma visão holística, integrando 0 ambiente natural e 0 material sem maiores aprofundamentos. 


\section{A Educação Ambiental nos Parâmetros Curriculares Nacionais}

Os PCN foram elaborados com a intenção de originar uma transformação positiva no sistema educacional brasileiro. Eles propõem que as questões que apresentem relevância social, aí se incluindo o meio ambiente, sejam tratadas na perspectiva transversal, sendo um compromisso partilhado com profissionais de todas as áreas, em níveis crescentes de complexidade e articulados à escolha e tratamento dos conteúdos.

Os PCN do terceiro e quarto ciclos do ensino fundamental, no âmbito das Ciências Naturais, indicam a necessidade de construção de uma escola voltada para a formação de cidadãos, que amplie e aprofunde um debate educacional, envolvendo toda a comunidade escolar. Indicam, entre outros pontos, que o estudante deve ser visualizado como integrante, dependente e agente transformador do ambiente.

Segundo o MEC (1998, p. 17), os PCN, na apresentação dos temas transversais para o terceiro e quarto ciclos do Ensino Fundamental, devem ter compromisso com a construção da cidadania, realizando uma prática educacional comprometida com a realidade social, com os direitos e responsabilidades relativos à vida pessoal e coletiva, e com a afirmação da participação política.

Ao proporem uma educação voltada para a cidadania, os PCN (MEC,1998, p. 23) se orientaram por uma base constitucional, voltada para: a dignidade da pessoa humana; a igualdade de direitos; a participação; e a corresponsabilidade pela vida social, todos princípios inseridos na Constituição Federal (BRASIL, 1986). Elegendo a cidadania como eixo articulador da educação, a escola se coloca contra as práticas sociais que não consideram os princípios a ela relacionados.

Os PCN (MEC, 1998, p. 23) afirmam que a sociedade é contraditória, plural e polissêmica, por ser constituída por diferentes classes e grupos sociais, o que implica na existência de múltiplos pontos de vista. Cabe, no entanto, destacar as quatro dimensões que orientam a escolha dos temas transversais. São elas: urgência social (questões graves que se apresentam como obstáculo à concretização da cidadania); abrangência nacional (algo que aconteça em toda ou quase toda dimensão do país); possibilidade de ensino-aprendizagem no ensino fundamental (algo que esteja de acordo com a faixa etária dos alunos); e favorecimento da compreensão e participação na realidade social (algo que permita aos alunos desenvolverem a capacidade de posicionar-se, superando a indiferença e intervindo de forma responsável) (MEC, 1998, p. 26).

Este documento aborda ainda dois conceitos: transversalidade $\mathrm{e}$ interdisciplinaridade. No que tange à transversalidade, como se trata de questões sociais com uma natureza diferente das áreas convencionais, constituem processos que estão sendo vividos intensamente pela sociedade, comunidade, famílias, alunos, professores. "Caberá aos professores mobilizar tais conteúdos em torno de temáticas escolhidas, de forma que as diversas 
áreas não representem continentes isolados, mas digam respeito aos diversos aspectos que compõem o exercício da cidadania" (MEC, 1998, p. 28).

Já a interdisciplinaridade implica na inter-relação e influência que existe entre os diferentes conteúdos, sejam eles do currículo convencional ou dos temas transversais. Ela questiona a visão disciplinar, compartimentada, da realidade, que ainda é muito corriqueira nas escolas. Transversalidade e interdisciplinaridade criticam a realidade como um conjunto de dados estáveis. Elas "apontam a complexidade do real e a necessidade de considerar a teia de relações entre os seus diferentes e contraditórios aspectos". A interdisciplinaridade diz respeito "a uma abordagem epistemológica dos objetos de conhecimento" (MEC, 1998, p. 30) e a transversalidade refere-se, principalmente, à dimensão didática

\section{Política Nacional de Educação Ambiental e Diretrizes Curriculares Nacionais}

A Lei Federal n. 9.795/99 constitui um grande marco na Educação Ambiental por instituir a Política Nacional para a Educação Ambiental (PNEA). Nela são definidos os princípios relativos à Educação Ambiental que deverão ser seguidos em todo o País. A lei estabelece que todos têm o direito à Educação Ambiental e a insere como um "componente essencial e permanente da educação nacional, devendo estar presente em todos os níveis e modalidades do processo educativo, em caráter formal e não formal" (art. $2^{\circ}$ ), como tema transversal, sem constituir disciplina específica. Deve funcionar como uma prática integrada, envolvendo todos os professores.

Assim, foram retirados alguns de seus princípios básicos e objetivos que servem de subsídio à construção de um projeto escolar de aprendizagem em Educação Ambiental. São eles: (a) ter um enfoque humanista, holístico, democrático e participativo; (b) considerar o meio ambiente em sua totalidade (o natural, o socioeconômico e o cultural), sob a visão da sustentabilidade; (c) admitir o pluralismo de ideias e concepções pedagógicas, na perspectiva da inter, multi e transdisciplinaridade; (d) vincular ética, educação, trabalho e práticas sociais no tratamento do tema; (e) garantir a avaliação crítica do processo educativo.

Já os objetivos selecionados foram: (a) desenvolver uma concepção integrada de meio ambiente (múltiplas e complexas relações); (b) democratizar as informações sobre meio ambiente; (c) fortalecer a consciência crítica sobre a problemática ambiental; (d) contribuir para preservação do meio ambiente, valorizando a qualidade ambiental como valor de cidadania; (e) valorizar uma sociedade ambientalmente equilibrada, fundada nos princípios de liberdade, igualdade, solidariedade, democracia, justiça social, responsabilidade e sustentabilidade; (f) fomentar a integração da Educação Ambiental com ciência e tecnologia; (g) fortalecer a cidadania, autodeterminação dos povos e solidariedade como fundamentos para o futuro da humanidade. 
Cabe, no entanto, esclarecer que esta Lei é a base da resolução n. 2, de 15 de junho de 2012, que estabelece as Diretrizes Curriculares Nacionais para a Educação. Tais Diretrizes reconhecem a relevância e a obrigatoriedade da Educação Ambiental, percebendo-a como importante instrumento de estruturação da educação no sentido de inserir valores e práticas transformadores e emancipatórios, cada vez mais necessários, face à realidade atual.

Dessa forma pode-se dizer que a Educação Ambiental escolar no Brasil está amparada pela legislação e deve acontecer em todas as esferas do ensino. Educar com o viés da Educação Ambiental não é tarefa fácil, pois tratase de um ato de estimular mudanças nos hábitos culturais, sociais e até mesmo econômicos, buscando um enfoque interdisciplinar, presente na Lei $n$. $9.795 / 99$.

No capítulo 1 das Diretrizes Nacionais Curriculares da Educação Ambiental (BRASIL, 2012, p. 70), são definidos os princípios que norteiam a Educação Ambiental, a partir do que dispõe a Lei no 9.795, de 1999. São eles:

(a) totalidade como categoria de análise fundamental em formação, análises, estudos e produção de conhecimento sobre o meio ambiente;

(b) interdependência entre o meio natural, o socioeconômico e o cultural, sob o enfoque humanista, democrático e participativo;

(c) pluralismo de ideias e concepções pedagógicas;

(d) vinculação entre ética, educação, trabalho e práticas sociais na garantia de continuidade dos estudos e da qualidade social da educação;

(e) articulação na abordagem de uma perspectiva crítica e transformadora dos desafios ambientais a serem enfrentados pelas atuais e futuras gerações, nas dimensões locais, regionais, nacionais e globais; $\mathrm{e}$

(f) respeito à pluralidade e à diversidade, seja individual, coletiva, étnica, racial, social e cultural, disseminando os direitos de existência e permanência e 0 valor da multiculturalidade e plurietnicidade do país e do desenvolvimento da cidadania planetária. Aproveitou-se esses princípios na construção do instrumento.

Cabe salientar que um último recorte foi considerado, a saber: o Projeto Político Pedagógico de uma escola, tomando-se quatro pilares que, geralmente, são encontrados neste documento, em qualquer escola. São eles:

(a) o PPP responde aos anseios da comunidade?

(b) está adequado à realidade escolar?

(c) promove o trabalho em equipe? e (d) concretiza a aprendizagem coletiva? 


\section{Procedimentos Metodológicos}

Uma vez definidos os pontos básicos a serem tomados como referência no processo avaliativo, estabeleceu-se os procedimentos necessários à construção do instrumento, a saber: indicação da abordagem avaliativa e dos participantes do estudo; elaboração do Quadro de Categorias Avaliativas; realização do processo de criação e validação do instrumento por especialistas em avaliação e Educação Ambiental; indicação dos padrões de julgamento para avaliar os projetos de aprendizagem em Educação Ambiental.

\section{Abordagem avaliativa e participantes do estudo}

$O$ estudo fundamenta-se no entendimento de que avaliar um projeto de Educação Ambiental demanda o conhecimento e a sabedoria de especialistas, que podem acrescentar contribuições importantes na análise de um instrumento de avaliação. Dessa forma, a abordagem escolhida para embasar este estudo foi a 'centrada nos especialistas', que se caracteriza, segundo Worthen, Sanders e Fitzpatrick (2004), pela necessidade de conhecimentos peculiares de um profissional em sua área de atuação para julgar o objeto avaliado. Ela pode ser dividida em quatro categorias, de acordo com a estrutura de cada uma: sistemas formais e informais, ou com um ou mais especialistas. Neste estudo foi considerada a categoria "parecer ad hoc individual", que na compreensão de Worthen, Sanders e Fitzpatrick (2004 p. 190) "é o ubíquo parecer a respeito de uma entidade emitido por um profissional selecionado por seus conhecimentos especializados para julgar o valor dessa entidade". A escolha dessa abordagem se deveu ao fato de a mesma contemplar os aspectos do instrumento a ser avaliado, além de basearse na experiência, qualificação, destreza e conhecimento do especialista.

Para realizar o trabalho de campo foram definidos três grupos de participantes. O primeiro grupo ficou composto por três especialistas com experiência em Avaliação, encarregados de avaliar a parte técnica do instrumento; o segundo, formado por outros três especialistas com competência para avaliar o conteúdo relativo ao desenvolvimento de projetos educacionais em Educação Ambiental. Estes buscaram responder a seguinte pergunta: o instrumento concretiza as diferentes perspectivas inseridas no Quadro de Categorias e Indicadores?

O terceiro grupo foi formado por seis professoras do Colégio Pedro II, campus Humaitá II, responsáveis pela realização de Projetos de Educação Ambiental. Essas docentes realizaram a pré-testagem do instrumento em quatro projetos de Educação Ambiental ali desenvolvidos.

Portanto, o instrumento aqui proposto, em sua validação, passou por seis especialista e na sua pré-testagem foi avaliado por mais seis especialistas, o que deu o total de 12 avaliadores. 


\section{O Quadro de Categorias que orientou o processo avaliativo}

Uma análise do conteúdo teórico abordado no item dois permitiu que se extraísse as categorias avaliativas e seus respectivos indicadores. Com este Quadro 1 foi possível construir as perguntas que iriam compor o instrumento.

Quadro 1: Categorias e Indicadores

\begin{tabular}{|c|c|}
\hline $\begin{array}{c}\text { Categorias de } \\
\text { Avaliação }\end{array}$ & Indicadores \\
\hline $\begin{array}{l}\text { Projetos de } \\
\text { Aprendizagem em } \\
\text { Educação } \\
\text { Ambiental }\end{array}$ & $\begin{array}{l}\text { - } \text { participação do estudante no tema de estudo e nas questões que o } \\
\text { completam; } \\
\text { - } \text { formulação do problema de estudo pelo estudante; } \\
\text { - } \text { uso de uma metodologia que inclua dúvidas, desafios e problematizações; } \\
\text { - } \quad \text { relação entre os conhecimentos dados no projeto e os saberes do } \\
\text { estudante; } \\
\text { - } \\
\text { apreensão de conceitos / ideias, em um processo de construção coletiva } \\
\text { proporcionando a aprendizagem de forma colaborativa e cooperativa; } \\
\text { - } \text { solução de problemas, relacionando-a às vivências; } \\
\text { - exercício do respeito mútuo; } \\
\text { - interação dos estudantes com seus colegas e outros atores sociais; } \\
\text { - } \text { construção do conhecimento pelo/a estudante. }\end{array}$ \\
\hline $\begin{array}{l}\text { Visão crítica da } \\
\text { prática de } \\
\text { Educação } \\
\text { Ambiental }\end{array}$ & $\begin{array}{l}\text { - visão do problema socioambiental de forma integrada / complexa; } \\
\text { - busca a mobilização dos alunos para a intervenção na realidade e nos } \\
\text { problemas socioambientais; } \\
\text { - promoção da autocrítica dos alunos; } \\
\text { - articulação entre a escola e o ambiente local / regional; } \\
\text { - busca da melhoria dos problemas e dos conflitos ambientais com a vista à } \\
\text { formação de uma cidadania ambiental; }\end{array}$ \\
\hline $\begin{array}{l}\text { Lei de Diretrizes e } \\
\text { Bases da } \\
\text { Educação } \\
\text { Nacional (LDBEN) }\end{array}$ & $\begin{array}{l}\text { - desenvolvimento de uma visão holística, relacionando o ambiente natural e o } \\
\text { material. }\end{array}$ \\
\hline $\begin{array}{l}\text { Parâmetros } \\
\text { Curriculares } \\
\text { Nacionais (PCN) - } \\
\text { Ciências Naturais } \\
\text { (O projeto como...) }\end{array}$ & $\begin{array}{l}\text { - tema transversal inserido na realidade local; } \\
\text { - flexibilização do currículo, introduzindo novas questões socioambientais; } \\
\text { - intervenção na realidade socioambiental local, por partes dos estudantes; } \\
\text { - reflexão sobre a teia de relações existentes nos projetos socioambientais e } \\
\text { seus contraditórios aspectos. }\end{array}$ \\
\hline $\begin{array}{l}\text { Política Nacional } \\
\text { de Educação } \\
\text { Ambiental (Lei n. } \\
\text { 9.795, de } 27 \text { de } \\
\text { abril de 1999.) }\end{array}$ & $\begin{array}{l}\text { - enfoque democrático e participativo; } \\
\text { - pluralismo de ideias; } \\
\text { - vinculação da ética à educação, ao trabalho e às práticas sociais; } \\
\text { - avaliação crítica do processo educativo; } \\
\text { - consciência crítica sobre a problemática socioambiental; } \\
\text { - defesa da qualidade ambiental como um valor inseparável da cidadania. }\end{array}$ \\
\hline $\begin{array}{l}\text { Diretrizes } \\
\text { Curriculares } \\
\text { Nacionais para a } \\
\text { Educação } \\
\text { Ambiental }\end{array}$ & $\begin{array}{l}\text { - democratização do acesso às informações referentes à área socioambiental; } \\
\text { - participação individual e coletiva, permanente e responsável; } \\
\text { - fortalecimento da integração ciência e tecnologia, visando à sustentabilidade } \\
\text { socioambiental; } \\
\text { - promoção do diálogo para a convivência e a paz. }\end{array}$ \\
\hline $\begin{array}{l}\text { Projeto Político } \\
\text { Pedagógico de } \\
\text { qualquer Colégio }\end{array}$ & $\begin{array}{l}\text { - contribuição para a materialização dos anseios da comunidade; } \\
\text { - adequação à realidade da comunidade escolar; } \\
\text { - favorecimento do trabalho conjunto, desenvolvendo a aprendizagem coletiva; } \\
\text { - criação de espaços para ações em equipe; }\end{array}$ \\
\hline
\end{tabular}

Fonte: As autoras (2017). 


\section{O processo de criação e validação do instrumento de avaliação}

$O$ instrumento escolhido para avaliar foi a Lista de Verificação (checklist), pois ele permite que sejam feitas mais perguntas aos participantes. Segundo Leite (2012, p. 104), "as listas de verificação têm sido consideradas uma das ferramentas mais simples e práticas para a gestão de processos e garantia da qualidade".

A primeira versão dessas Listas foi submetida à validação de três especialistas em Avaliação que avaliaram a sua construção técnica. Ao mesmo tempo, foi também validado o seu conteúdo por outros três especialistas em Educação Ambiental.

Foram escritas duas cartas convidando os especialistas em avaliação e em conteúdo para a tarefa de validarem a lista. Nestas cartas explicou-se o que se esperava de cada grupo de avaliadores, indicando-se também os valores para cada opção assinalada. Cada resposta afirmativa (Sim) valia um ponto, enquanto as respostas Não e Não se Aplica valiam zero. Isto significaria que se projeto tivesse todos os itens marcados em Sim, teria um total de 33 pontos.

Sabendo-se que seria muito difícil um projeto contemplar todos esses pontos, estabeleceu-se o seguinte julgamento para expressar os resultados da avaliação:
a) 25 ou mais questões assinaladas com sim - projeto relevante;
b) de 18 a 24 questões marcadas com sim - projeto razoável;
c) de 10 a 17 questões com sim - projeto precisando de ajustes;
d) de 1 a 9 questões com sim - o projeto deve ser reformulado.

\section{Resultados}

Após o processo de validação, o instrumento ficou com o formato que se segue. Foi, então, pré-testado pelos seis docentes do Colégio Pedro II, que responderam às perguntas considerando seus projetos de Educação Ambiental. 
Categoria: Projetos de Aprendizagem em Educação Ambiental (EA)

\begin{tabular}{|l|l|l|l|l|}
\hline Indicador & Sim & Não & $\begin{array}{l}\text { Não se } \\
\text { aplica }\end{array}$ & $\begin{array}{l}\text { Justificativa/ } \\
\text { Comentário }\end{array}$ \\
\hline $\begin{array}{l}1.1 \text { O estudante participou da escolha do tema a ser } \\
\text { abordado }\end{array}$ & & & \\
\hline $\begin{array}{l}1.2 \text { O problema de estudo foi formulado com o/ a } \\
\text { estudante. }\end{array}$ & & & \\
\hline $\begin{array}{l}1.3 \text { Foi desenvolvida uma metodologia que incluía } \\
\text { dúvidas. desafios e problematizações. }\end{array}$ & & & \\
\hline $\begin{array}{l}1.4 \text { Foi estabelecida relação entre os conhecimentos } \\
\text { do projeto e os saberes do estudante. }\end{array}$ & & & \\
\hline $\begin{array}{l}1.5 \text { Foi desenvolvido o processo de apreensão de } \\
\text { conceitos / ideias como uma construção coletiva. }\end{array}$ & & & & \\
\hline $\begin{array}{l}1.6 \text { Houve construção do conhecimento por parte do } \\
\text { (a) estudante. }\end{array}$ & & & \\
\hline $\begin{array}{l}1.7 \text { A capacidade de reconhecer e encaminhar os } \\
\text { problemas, ainda que não sejam solucionados, } \\
\text { relaciona-se com as vivências dos alunos. }\end{array}$ & & & & \\
\hline 1.8 Houve o exercício do respeito mútuo. & & & & \\
\hline $\begin{array}{l}1.9 \text { Ocorreu a interação dos (as) estudantes com os } \\
\text { (as) seus (suas) colegas e outros (as) atores sociais. }\end{array}$ & & & & \\
\hline
\end{tabular}

Categoria: Educação Ambiental Crítica

\begin{tabular}{|l|l|l|l|l|}
\hline Indicador & Sim & Não & $\begin{array}{l}\text { Não se } \\
\text { aplica }\end{array}$ & $\begin{array}{l}\text { Justificativa/ } \\
\text { Comentário }\end{array}$ \\
\hline $\begin{array}{l}2.1 \text { Ocorreu a observação da realidade } \\
\text { socioambiental de forma integrada/complexa? }\end{array}$ & & & \\
\hline $\begin{array}{l}2.2 \text { Houve mobilização dos (as) estudantes para } \\
\text { a intervenção na realidade e nos problemas } \\
\text { socioambientais. }\end{array}$ & & & & \\
\hline $\begin{array}{l}2.3 \text { Houve autocrítica por parte dos (as) } \\
\text { estudantes. }\end{array}$ & & & \\
\hline $\begin{array}{l}2.4 \text { Houve articulação da escola com o ambiente } \\
\text { local/regional. }\end{array}$ & & & \\
\hline $\begin{array}{l}2.5 \text { Ocorreu a formação de uma cidadania } \\
\text { ambiental. }\left({ }^{*}\right)\end{array}$ & & & & \\
\hline
\end{tabular}

$\left({ }^{*}\right)$ Cidadania ambiental: A cidadania ambiental tem por base a consciência de que ações locais interferem ou refletem, direta ou indiretamente em todo o mundo; é o pensar global e atuar localmente.

Categoria: Lei de Diretrizes e Bases da Educação Nacional (LDBEN)

\begin{tabular}{|l|l|l|l|l|}
\hline Indicador & Sim & Não & $\begin{array}{l}\text { Não se } \\
\text { aplica }\end{array}$ & $\begin{array}{l}\text { Justificativa/ } \\
\text { Comentário }\end{array}$ \\
\hline $\begin{array}{l}\text { 3.1 O projeto desenvolveu uma visão holística, } \\
\text { sobre o ambiente natural e o social. }\end{array}$ & & & & \\
\hline
\end{tabular}


Categoria: Parâmetros Curriculares Nacionais (PCN)

\begin{tabular}{|l|l|l|l|l|}
\hline Indicador Sim & Não & $\begin{array}{l}\text { Não se } \\
\text { aplica }\end{array}$ & Justificativa/Comentário \\
\hline 4.1 Foram inseridos temas transversais. & & & & \\
\hline $\begin{array}{l}4.2 \text { O projeto foi flexibilizado para a } \\
\text { introdução de novas questões }\end{array}$ & & & & \\
socioambientais. & & & \\
\hline $\begin{array}{l}4.3 \text { Houve intervenção na realidade por } \\
\text { parte dos estudantes com ações }\end{array}$ & & & & \\
socioambientais. & & & \\
\hline $\begin{array}{l}\text { 4.4 Houve reflexão sobre a teia de } \\
\text { relações existentes no projeto e seus } \\
\text { contraditórios aspectos. }\end{array}$ & & & \\
\hline
\end{tabular}

Categoria: Política Nacional de Educação Ambiental

\begin{tabular}{|l|l|l|l|l|}
\hline Indicador & Sim & Não & $\begin{array}{l}\text { Não se } \\
\text { aplica }\end{array}$ & $\begin{array}{l}\text { Justificativa/ } \\
\text { Comentário }\end{array}$ \\
\hline 5.1 Foi estabelecida a participação democrática. & & & & \\
\hline $\begin{array}{l}5.2 \text { O pluralismo de ideias esteve presente ao } \\
\text { longo do projeto. }\end{array}$ & & & & \\
\hline 5.3 Vinculou-se a ética à Educação Ambiental. & & & & \\
\hline $\begin{array}{l}5.4 \text { Houve avaliação crítica do processo } \\
\text { educativo. }\end{array}$ & & & & \\
\hline $\begin{array}{l}5.5 \text { Foi praticada a consciência crítica sobre a } \\
\text { problemática socioambiental. }\end{array}$ & & & \\
\hline $\begin{array}{l}5.6 \text { A defesa da qualidade ambiental como um } \\
\text { valor inseparável da cidadania fez parte do } \\
\text { processo de construção do conhecimento. }\end{array}$ & & & & \\
\hline
\end{tabular}

Categoria: Diretrizes Nacionais Curriculares da Educação Ambiental

\begin{tabular}{|l|l|l|l|l|}
\hline Indicador & Sim & Não & $\begin{array}{l}\text { Não se } \\
\text { aplica }\end{array}$ & $\begin{array}{l}\text { Justificativa/ } \\
\text { Comentário }\end{array}$ \\
\hline $\begin{array}{l}6.1 \text { O projeto garante a democratização e o } \\
\text { acesso às informações referentes à área } \\
\text { socioambiental. }\end{array}$ & & & & \\
\hline $\begin{array}{l}\text { 6.2 Desenvolveu-se a participação individual e } \\
\text { coletiva dos (as) estudantes. }\end{array}$ & & & & \\
\hline $\begin{array}{l}\text { 6.3 O projeto possibilitou a integração entre } \\
\text { ciência e tecnologia, visando à sustentabilidade } \\
\text { socioambiental. }\end{array}$ & & & & \\
\hline $\begin{array}{l}\text { 6.4 O diálogo para a convivência e a paz foi } \\
\text { desenvolvido ao longo do projeto. }\end{array}$ & & & & \\
\hline
\end{tabular}

Categoria: Projeto Político Pedagógico de um Colégio

\begin{tabular}{|l|l|l|l|l|}
\hline Indicador & Sim & Não & $\begin{array}{l}\text { Não se } \\
\text { aplica }\end{array}$ & $\begin{array}{l}\text { Justificativa/ } \\
\text { Comentário }\end{array}$ \\
\hline $\begin{array}{l}7.1 \text { O projeto contribuiu para a materialização } \\
\text { dos anseios da comunidade. }\end{array}$ & & & & \\
\hline $\begin{array}{l}7.2 \text { Houve adequação do projeto à realidade } \\
\text { da comunidade escolar. }\end{array}$ & & & & \\
\hline $\begin{array}{l}7.3 \text { O trabalho em conjunto favoreceu o } \\
\text { trabalho em equipe. }\end{array}$ & & & & \\
\hline 7.4 A aprendizagem coletiva foi estabelecida. & & & & \\
\hline
\end{tabular}

Revbea, São Paulo, V. 14, № 1: 439-455, 2019. 
Tratou-se, portanto de um pré-teste realizado em situação real, e que deu informações relevantes para que se respondesse às questões do estudo.

\section{Considerações finais}

A validação do instrumento, realizada por seis especialistas (três em Educação Ambiental e três em Avaliação), apontou a necessidade de serem realizadas algumas mudanças importantes para o seu aprimoramento. Já os pré-testes, realizados por um total de outros seis professores, que utilizaram o instrumento para avaliar seus projetos de Educação Ambiental, revelaram que ele é adequado nesta tarefa. Eles também indicaram que a Lista de Verificação atende às necessidades dos professores que trabalham com projetos escolares de Educação Ambiental, uma vez que suas perguntas estão em conformidade com a Legislação vigente referente à Educação Ambiental. Indicaram, ainda, que a Lista de Verificação criada possui características que confere qualidade técnica, importância e praticidade ao instrumento.

A Lista de Verificação, ao articular a legislação referente à Educação Ambiental escolar com o Projeto Político Pedagógico (PPP) de uma escola, pode ter os reajustes necessários ao seu aprimoramento, levando em conta o que se expressa neste documento.

No total foram 33 itens para sete Categorias. Considerando que quatro projetos foram avaliados (pré-testados), sendo que alguns deles mais de uma vez, o que forneceu um total de sete pré-testes realizados, obteve-se um total de 231 (33 vezes 7) itens respondidos pelos seis professores. Das 231 respostas, 22 foram respondidas com não, o que representa $16,7 \%$ do total, evidenciando que, apesar de existirem aspectos que podem ser melhorados em alguns projetos, a maior parte dos itens atende às demandas do instrumento e apresenta resultado condizente com a avaliação 'projetos relevantes'. Apenas um projeto, avaliado por duas professoras no campus Humaitá II, ainda que apresentasse relevância, precisaria ser reformulado. Todos os outros projetos avaliados por meio das Listas de Verificação atingiram a pontuação referente a "projeto relevante".

Assim, retomando as questões avaliativas deste estudo, pode-se afirmar: (a) o instrumento atende às demandas expressas na Legislação que norteiam a prática da Educação Ambiental. As categorias e indicadores referentes a esses aspectos foram os que mais obtiveram a marcação sim; (b) o instrumento atende à categoria 'perspectiva crítica em Educação Ambiental', pois esta categoria apresentou respostas positivas na maioria dos respondentes (com apenas uma resposta negativa e duas "não se aplica").

Cabe ainda ressaltar que os itens: "O estudante participou na escolha do tema a ser abordado" (1.1) e "O problema de estudo foi formulado com o estudante" (1.2), foram assinalados em cinco pré-testes como não, sugerindo que, na maior parte dos projetos os estudantes não participaram da escolha do tema ou o mesmo não foi formulado pelos estudantes. Ocorre que, algumas vezes, os projetos são sugeridos pelos professores, ou são oriundos de 
diversas demandas que surgem no cotidiano escolar. Neste caso, é importante que o professor solicite aos estudantes a sua participação na escolha ou elaboração do tema.

Por fim, durante a aplicação dos pré-testes, observou-se que a Lista de Verificação pode servir também como um guia de orientação a ser seguido na elaboração de projetos escolares de Educação Ambiental. Ficou nítido que as questões inseridas na Lista de Verificação podem ajudar os professores a construírem seus projetos de aprendizagem, pois elas recuperam aspectos importantes que se encontram na legislação educacional sobre Educação Ambiental escolar.

A articulação da legislação vigente com o PPP do colégio traz orientações relevantes para os projetos, destacando detalhes importantes. Tais detalhes devem ser considerados no processo de elaboração de projetos escolares de Educação Ambiental, para garantir a execução de ações pretendidas.

Entende-se que este estudo, além de propiciar a criação de uma Lista de Verificação que serve, tanto para avaliar projetos como também para planejálos, possibilitou o exercício de se colocar a teoria em prática. A partir da aplicação do instrumento pode-se romper com a dicotomia entre o conteúdo e a forma - entre a teoria e a prática - no processo educacional. Deste modo, obteve-se a reflexão sobre a importância de se avaliar a prática de projetos escolares de Educação Ambiental, na perspectiva da Educação Ambiental crítica. Nesta direção, o objetivo do estudo: construir, validar e pré-testar um instrumento de avaliação de projetos escolares de Educação Ambiental, foi atingido.

\section{Referências}

BRASIL. Constituição da República Federativa do Brasil. Brasília, DF: Senado Federal: Centro Gráfico, 1988. Disponível em: $<$ https://www.jusbrasil.com.br/topicos/10645403/inciso-vi-do-paragrafo-1-doartigo-225-da-constituicao-federal-de-1988>. Acesso: 4 fev. 2017.

BRASIL. Lei no 9.394 de 20 de dezembro de 1996. Estabelece as diretrizes e bases da educação nacional. Diário Oficial da União, Brasília, DF, 23 dez. 1996. Disponível em: <https://www2.senado.leg.br/bdsf/bitstream/handle/id/ 70320/65.pdf>. Acesso: 15 jan. 2017.

BRASIL. Lei $n^{\circ} 9.795$ de 27 de abril de 1999. Dispõe sobre a Educação Ambiental, institui a Política Nacional de Educação Ambiental e dá outras providências. Diário Oficial da União, Brasília, DF, 28 abr. 1999. Disponível em: $<$ http://www.planalto.gov.br/ccivil 03/leis/L9795.htm>. Acesso: 17 abr. 2017.

BRASIL. Resolução no 2, de 15 de junho de 2012. Estabelece as diretrizes curriculares nacionais para a Educação Ambiental. Diário Oficial da União, Brasília, DF, 18 jun. 2012. Disponível em: <http://portal.mec.gov.br/index.php? option=com docman\&view=download\&alias=10988-rcp002-12-pdf\&category slug=maio-2012-pdf\&ltemid=30192 >. Acesso em: 17 abr. 2017.

Revbea, São Paulo, V. 14, № 1: 439-455, 2019. 
DIAS, G.F. Educação Ambiental: princípios e práticas. São Paulo: Gaia, 2004. FAGUNDES, L.C.; SATO, L.S.; MAÇADA, D.L. Aprendizes do futuro: as inovações começaram. Brasília, DF: Ministério da Educação, 2008.

GUIMARÃES, M. Educação Ambiental crítica. In: LAYRARGUES, P.P. Identidades da Educação Ambiental brasileira. Brasília, DF: Ministério do Meio Ambiente, 2004. Disponível em: <http://www.mma.gov.br/ estruturas/educamb/ arquivos/livro ieab.pdf>. Acesso: 24 mar. 2017.

LEITE, L. Lista de verificação. In: ELLIOT, L.G. (Org). Instrumentos de Avaliação e Pesquisa: caminhos para construção e validação. Rio de Janeiro: Wak, 2012.

LOUREIRO, C.F.B. Educação Ambiental crítica: contribuições e desafios. In: MELLO, S.S.; TRAJBER, R. (Org.). Vamos cuidar do Brasil: conceitos e práticas em Educação Ambiental na escola. Brasília, DF: Ministério da Educação; UNESCO, 2007. Disponível em: <http://www.dominiopublico.gov.br /download/texto/me004660.pdf>. Acesso: 22 mar. 2017.

MINISTÉRIO DA EDUCAÇÃO (Brasil). Portaria n $\cong 2421$ de 1991. Instituiu, em caráter permanente, um Grupo de Trabalho de EA com o objetivo de definir, juntamente com as Secretarias Estaduais de Educação. Brasília, DF: MEC, 1991. Disponível em: <http://www.dominiopublico.gov.br/download/ texto/me4556.pdf >. Acesso em: 16 nov. 2017.

MINISTÉRIO DA EDUCAÇÃO (Brasil). Parâmetros Curriculares Nacionais: Terceiro e quarto ciclos do Ensino Fundamental: Ciências Naturais. Brasília, DF: MEC/SEF, 1998. Disponível em: <http://portal.mec.gov.br/seb/arquivos/pdf/ ciencias.pdf>. Acesso em: 16 nov. 2017.

MINISTÉRIO DA EDUCAÇÃO (Brasil). Secretaria de Educação Fundamental. Políticas de melhoria da qualidade da educação: um balanço institucional: Educação Ambiental. Brasília, DF: MEC/SEFF, 2002. Disponível em: $<$ http://portal.mec.gov.br/seb/arquivos/pdf/Relat.pdf>. Acesso em: 16 nov. 2017. MINISTÉRIO DO MEIO AMBIENTE (Brasil). Parecer no 226 de 1987. Em relação a necessidade de inclusão da Educação Ambiental nos currículos escolares de $1^{\circ}$ e $2^{\circ}$ Graus. Brasília, DF: MEC, 1987. Disponível em: $<$ http://www.mma.gov.br/informma/itemlist/category/15-educacaoambiental?start=112>. Acesso em: 5 maio 2017.

MINISTÉRIO DO MEIO AMBIENTE (Brasil). Histórico Mundial. Brasília, DF: MMA, 2017. Disponível em: <http://www.mma.gov.br/educacao-ambiental/ politica-de-educacao-ambiental/historico-mundial>. Acesso em: 17 nov. 2017.

TREIN, D.; SCHLEMMER, E.D.R. Projetos de aprendizagem baseados em problema no contexto da web 2.0: possibilidades para a prática pedagógica. Revista E-Curriculum, São Paulo, v. 4, n. 2, p. 1-20, jun. 2009.

WORTHEN, B.R.; SANDERS, J.L.; FITZPATRICK, J.R. Avaliação de programas: concepções e práticas. São Paulo: Ed. Gente, 2004. 